\title{
Frequency and developmental timing of linear enamel hypoplasia defects in Early Archaic Texan hunter-gatherers
}

\author{
J. Colette Berbesque ${ }^{\text {Corresp., }}{ }^{1}$, Kara C Hoover ${ }^{2}$ \\ ${ }^{1}$ Centre for Research in Evolutionary, Social and Inter-Disciplinary Anthropology, University of Roehampton, London, United Kingdom \\ 2 Department of Anthropology, University of Alaska - Fairbanks, Fairbanks, Alaska, United States \\ Corresponding Author: J. Colette Berbesque \\ Email address: colette.berbesque@roehampton.ac.uk
}

Digital photographs taken under controlled conditions were used to examine the incidence of linear enamel hypoplasia defects (LEHs) in burials from the Buckeye Knoll archaeological site (41VT98 Victoria county, Texas), which spans the Early to Late Archaic Period (ca. 2500-6500 BP uncorrected radiocarbon). The majority (68 of 74 burials) date to the Texas Early Archaic, including one extremely early burial dated to 8,500 BP. The photogrammetric data collection method also results in an archive for Buckeye Knoll, a significant rare Archaic period collection that has been repatriated and reinterred. We analyzed the incidence and developmental timing of LEHs in permanent canines. Fifty-nine percent of permanent canines $(n=54)$ had at least one defect. There were no significant differences in LEH frequency between the maxillary and mandibular canines $(U=640.5$, $\mathrm{n} 1=37, \mathrm{n} 2=43, \mathrm{p}=.110$ ). The sample studied ( $\mathrm{n}=92$ permanent canines) had an overall mean of 0.93 LEH defect per tooth, with a median of one defect, and a mode of zero defects. Average age at first insult was 3.92 (median $=4.00$, range $=2.5-5.4$ ) and the mean age of all insults per individual was 4.18 years old (range $=2.5-5.67$ ). Age at first insult is consistent with onset of weaning stress-the weaning age range for huntergatherer societies is 1-4.5. Having an earlier age of first insult was associated with having more LEHs ( $n=54$, rho $=-0.381, p=0.005)$. 
1 Frequency and developmental timing of linear enamel hypoplasia defects in Early Archaic Texan

2 Hunter-Gatherers

3

4 J. Colette Berbesque ${ }^{1}$ and Kara C. Hoover ${ }^{2}$

$5 \quad$ *corresponding author: colette.berbesque@roehampton.ac.uk

6

$7{ }^{1}$ Centre for Research in Evolutionary, Social and Inter-Disciplinary Anthropology, University of

8 Roehampton, London SW15 4JD U.K.

9

${ }^{2}$ Department of Anthropology, University of Alaska, Fairbanks, AK 99709 U.S.A.

\section{Highlights}

14 - Our study population were hunter-gatherers spanning the Early to Late Archaic period

- We analyzed incidence and developmental timing of Linear Enamel Hypoplasia defects in canines

- Fifty-nine percent of canines in this population had one or more defects

- Average developmental age of first insult was is 3.92 years

- Having an earlier age of first insult was associated with having more LEHs 


\section{Abstract}

23

24

25

Digital photographs taken under controlled conditions were used to examine the incidence of linear enamel hypoplasia defects (LEHs) in burials from the Buckeye Knoll archaeological site (41VT98 Victoria county, Texas), which spans the Early to Late Archaic Period (ca. 2500-6500 BP uncorrected radiocarbon). The majority (68 of 74 burials) date to the Texas Early Archaic, including one extremely early burial dated to 8,500 BP. The photogrammetric data collection method also results in an archive for Buckeye Knoll, a significant rare Archaic period collection that has been repatriated and reinterred. We analyzed the incidence and developmental timing of LEHs in permanent canines. Fifty-nine percent of permanent canines $(n=54)$ had at least one defect. There were no significant differences in LEH frequency between the maxillary and mandibular canines $(\mathrm{U}=640.5, \mathrm{n} 1=37, \mathrm{n} 2=43, \mathrm{p}=$ .110). The sample studied ( $\mathrm{n}=92$ permanent canines) had an overall mean of 0.93 LEH defect per tooth, with a median of one defect, and a mode of zero defects. Average age at first insult was $3.92($ median $=4.00$, range $=2.5-5.4)$ and the mean age of all insults per individual was 4.18 years old (range $=2.5-5.67)$. Age at first insult is consistent with onset of weaning stress- the weaning age range for hunter-gatherer societies is $1-4.5$. Having an earlier age of first insult was associated with having more LEHs $(\mathrm{n}=54$, rho $=-0.381, \mathrm{p}=0.005)$. 


\section{Introduction}

The Buckeye Knoll site (41VT98) contains a prolonged record of short-term continuous site use over a period of 8,000 years $(8,500-500 \mathrm{BP})$ with evidence of resource caching for future occupations. We know very little about Archaic life history and Buckeye Knoll constitutes one of the largest populations available for testing hypotheses regarding health and disease in this early period of North American prehistory. Excavation uncovered 75 discrete burial loci and recovered a minimum number of 116 individuals that were dated to $8500-3500 \mathrm{BP}$ using tooth and bone collagen samples. Buckeye Knoll was exhumed and reburied in compliance with the Native American Graves Protection and Repatriation Act (NAGPRA), so any future data collection or analysis must come from the digital photographs collected for archival purposes (Ricklis et al., 2012c).

Dental enamel hypoplasia defects represent an interruption in the growth process of teeth and can be attributed to genetics (Brook, 2009; Hart et al., 2002; Zilberman et al., 2004), trauma (Brook, 2009), and insult (Goodman, 1988; Sarnat and Schour, 1942; Sarnat and Schour, 1941). Those linked to external biological insult (e.g., foreign disease pathogen, injury) develop when resources normally directed to growth and development are rerouted to defending the body or are only insufficient to sustain maintenance activities (e.g., malnourishment, diarrhea) (Sarnat and Schour, 1942; Sarnat and Schour, 1941). Enamel hypoplastic defects occur on the buccal and labial surfaces of teeth and mostly commonly manifest as transverse grooves, or linear enamel hypoplasia (LEH), but also can appear as pits or grooves (Hillson and Bond, 1997). Because teeth do not remodel, defects captured during growth and development are permanent and have been used to infer early life health in a number of populations (e.g. Berbesque and Doran, 2008; Guatelli-Steinberg et al., 2004; Hoover and Matsumura, 2008; Lieverse et al., 2007; Temple, 
64 2010). Of particular note are the associations between weaning stress (e.g. Herring et al., 1998;

65 Katzenberg et al., 1996; Moggi-Cecchi et al., 1994) and earlier age at death (DeWitte and

66 Stojanowski, 2015; Walter and DeWitte, 2017; Yaussy et al., 2016).

67 A major shift in dietary pattern and environmental adaptations occurred in the southern

68

United States during the transition from early to mid-Holocene. This period was a time of dramatic worldwide changes in temperature, sea level, and coastal 'configuration'. Buckeye Knoll may have been in a period of climatic transition, the severity of which is unknown. The climate reconstruction of Buckeye Knoll was primarily from palynology. Two cores were taken from the Guadalupe River Flood Plain adjacent to the Buckeye Knoll Site for palynological analysis. These cores enable a regional vegetation reconstruction extending back to $9500 \mathrm{cal}$. B. P. until present. During this period, there were marked changes in climate reflected in the pollen taxa represented, particularly circa $6000 \mathrm{BP}$ when climate change resulted in enough increases in upland-prairie biomass that it may have caused a shift in subsistence strategy (Ricklis et al., 2012a). This might be a factor in the overall levels of systemic stress in populations of this time period, such as Buckeye Knoll. Here, we aim to infer nonspecific nutritional and developmental stresses via the developmental timing and frequency of linear enamel hypoplasia defects (LEH) in the canines using photogrammetric methods.

\section{Methods}

Study Site Description

The first evidence for human activity at Buckeye Knoll dates to the Paleo-Indian period and consists of scattered artifacts, specifically stone darts. Prolonged occupation of the site begins in the Archaic period, which is marked by a variety of human activities linked to repeated short-term occupation. Primary artifacts include debitage, projectiles, tools, beads, bone, shell, 
88 and hearths. More recent artifacts include indigenous ceramics. The site record contains evidence

89 for a prolonged record of short-term continuous use for a period of 8,000 years (8,500-500 BP).

90 Of particular interest are large pits which may have been used to store food which suggests

91 longer occupations of up to a few months; even more interesting is evidence for material caching

92 which suggests intentional regular re-occupation (Ricklis et al., 2012c).

93 Faunal remains recovered from the site are abundant $-74,000$ identifiable fragments

94 representing a minimum of 126 vertebrate taxa including fish (mostly gar), small mammals

95 (often rodents), some large mammals (e.g., deer), and rarely birds. The pattern of resource

96 exploitation evidenced by faunal analysis suggests that opportunistic hunting of larger game was

97 gradually replaced by increased emphasis on net-fishing (evidenced by a shift from larger to

98 smaller fish body sizes) and wider exploitation of other taxa; this may be attributable to

99 increased population demands over time (Ricklis et al., 2012c) or the previously noted climate

100 change that resulted in changes to the local environment and possible dietary shifts in response to 101 that change.

102 A total of 75 discrete burials containing 119 individuals were excavated. The majority of

103 burials were single interment but there were also graves containing multiple individuals. All but

104 one burial (dated to the Late Archaic) were interred on the Knoll Top. Of the remaining 74

105 burials, the vast majority $(n=68)$ date to the Texas Early Archaic, including one extremely early

106 burial dated to 8,500 BP. The Texas Early Archaic burial dates tend to cluster between 7,400-

$1076300 \mathrm{BP}$ - the lack of non-mortuary activity at the site during the $7^{\text {th }}$ millennium (roughly 7,000 -

1086200 BP) suggests that the Knoll Top space was reserved exclusively for treatment of the dead

109 during this time (Ricklis et al., 2012b; Ricklis et al., 2012c). Texas Early Archaic burials are

110 associated with artifacts that form a unique mortuary assemblage that is closely related to Middle 
111 Archaic period (i.e., ca. 8,000-5,000 BP) cultures in the Mississippi Valley region and beyond.

112 Thus, this assemblage reflects larger regional cultural associations. During this period, flexed or

113 semi-flexed burials were most common followed by a smaller number of disarticulated

114 individuals, and an even smaller number of individuals interred in sitting postures. The Late

115 Archaic period was characterized by extended burials (Ricklis et al., 2012b).

\section{Photogrammetric Materials and Methods}

118 Photographs were used for data collection because the Buckeye Knoll sample was

reinterred. Reliability of LEH scoring is more robust in photogrammetric methods, with a significant increase in LEH number identified compared to direct examination method (Golkari Archaic population, Windover (Berbesque and Doran, 2008). Coolpix in macro mode. The diminished focal length presents some difficulty with depth or focus on anything other than one plane. As teeth are often curved, every attempt was made to capture the labial surface of the tooth with most clarity. Multiple photographs were taken from different angles to ensure defects were scorable. A metric scale was placed in the plane of the tooth surface in each photograph. The photographs were taken in high quality TIFF file format.

Missing teeth or teeth too worn to score were excluded from analysis. In some cases, dental calculus prevented an accurate measurement of crown height, and measurements were then taken

131 from the bottom of the calculus to the top of the crown. These measurements are primarily for 132 quality control in using an imaging software for analysis. 
134 of crown formation (7.5 months to 6.5 years for maxillary canines and 10.5 months to 5.5 years

135 for mandibular canines) (AlQahtani et al., 2014) and can best capture the peak window of

136 developmental stress caused by weaning (Sandberg et al., 2014). LEH was scored in Microsoft

137 Paint. Once scored, the images were imported into Scion Image for analysis (a PC friendly

138 software modeled after the National Institute of Health ImageJ, which is commonly used in 139 morphometrics studies) (Scion, 2000-2001).

Developmental timing of each defect was determined using the estimate by Reid and Dean

141 (Reid and Dean, 2000), which necessitates estimation of complete, unworn crown height for

142 every tooth. An estimate of completeness for each canine was based on surrounding dentition

143 and other canines within the population. The median percent complete for permanent dentition is

$14485 \%$ overall. Mandibular canines were $86 \%$ complete, and maxillary canines were $81 \%$

145 complete. This visual estimate of complete canine height provided a wear estimate for each

146 canine. Because this population has significant dental wear, stage of development for each

147 defect was determined by measuring the distance from the cemento-enamel junction to the

148 bottom of each defect rather than from the tip of the cusp down to the defect. All statistical

149 analysis was conducted using SPSS version 22. None of the variables met the assumptions of a

150 normal distribution, so nonparametric statistics were used for all analyses.

151 To place Buckeye Knoll in context with similar populations, data from this study were

152 compared to published data from populations dating to an average of 3000 years or older

153 contained in the public Global History of Human Health Database (Steckel and Rose, 2002) (see

154 Table 1). Buckeye Knoll was also compared with another Early Archaic population, Windover

$155(8,120-6,98014 \mathrm{C}$ years B.P. uncorrected), using the same methods deployed in this study 
156 (Berbesque and Doran, 2008).

157 Insert Table 1.

\section{Results}

There were 41 deciduous canines in the sample and 92 permanent canines. The permanent dentition consisted of 37 maxillary canines and 43 mandibular canines -12 could not be identified as maxillary or mandibular. The permanent dentition had a hypoplasia frequency rate of $59 \%(n=54$ canines with at least one hypoplastic defect) in the population. There was an overall mean of 0.93 defects per permanent canine, with a median of one defect, and a mode of zero defects. We did not analyse deciduous dentition for timing of defects. Out of 41 deciduous canines in the population, only one defect was found.

Despite limited demographic information available for these mostly isolated dentition, there were associated skeletal material for some individuals--allowing for a basic breakdown by sex and age category (adults versus juvenile with permanent dentition). Juveniles with

171 permanent dentition had higher rates of multiple defects than the general population (see Table

172 2). Table 2 provides breakdown of the sample by presenting frequency and portion of the 173 overall sample by LEH count (range $=0-4$ ) and demographic category.

174 Insert Table 2. earliest defect (Mann Whitney $\mathrm{U}=228$, earliest maxillary defect $\mathrm{N}=20$, earliest mandibular $\mathrm{N}=$

$17727, \mathrm{p}=.366)$ or number of defects $(\mathrm{U}=640.5$, maxillary defects $\mathrm{N}=37$, mandibular defects $\mathrm{N}=$ 
$17843, p=.110)$. The mean age for the earliest defect per individual was 3.92 (range $=2.5-5.4)$.

179 Individuals with more LEHs also had earlier age of first insult $(n=54$, rho $=-0.381, p=0.005)$.

180 The mean developmental age of all defects was 4.18 years old (range $=2.5-5.67$ ).

A comparative analysis of individual LEH frequency in Buckeye Knoll and populations

182 in the Global History of Human Health Database (Steckel and Rose, 2002) found that Buckeye

183 Knoll frequencies were significantly higher with one or more LEH on their canine (see Table 3)

$184($ Chi-Square $=58.425, \mathrm{df}=4, \mathrm{p}=0.000)$.

185 Insert Table 3.

LEH incidence in another Early Archaic population, Windover, was more than twice that

of Buckeye Knoll (see Table 4) (Berbesque and Doran, 2008). LEH data collection methods for both sites used the same photographic methods.

Insert Table 4.

\section{Discussion and Conclusions}

Juveniles with permanent dentition had the highest incidence of LEH. Also, greater numbers of individual LEH were associated with earlier age at death, providing some evidence for a mortality curve that would support the use of LEH as a stress indicator in this population and indicating social factors that warrant further investigation. This finding provides some evidence for the Barker Hypothesis; wherein individuals exposed to stressors earlier in life may actually have damaged immunological competence as a consequence of those stressors (Armelagos et al., 2009; Goodman and Armelagos, 1989).

The location of each defect gives insight into the timing of metabolic insult. Cusp enamel completion occurs at 1.7 years for maxillary canines and 0.98 years for mandibular canines (Reid 
201 and Dean, 2000). As the first period on the occlusal surface of the crown is often worn away by

202 attrition, much of the data on the second year of life is lost. Clustering of LEH around a location

203 on the tooth that corresponds to a particular age might indicate some stressful milestone event

204 whether culturally flexible (e.g. age of weaning) or not (e.g. birth). Weaning ages across hunter-

205 gatherer societies vary considerably, with New World hunter-gatherers weaning earlier

206 (mean=2.32 years old) than Old World hunter-gatherers (mean $=3.20$ years old) and a combined

207 range of 1 to 4.5 (Marlowe, 2005). Age of the mean earliest defect for Buckeye Knoll is within

208 this range $($ mean $=3.92)$, but late for the mean age of weaning in ethnographically described

209 hunter-gatherers in the New World. Perhaps the developmental timing of most LEH defects has

210 less to do with extreme stress from weaning and more with the more with the acute angles

211 formed by the Striae of Retzius relative to the enamel surface to enamel formation. It has been

212 suggested that these acute angles make even small disruptions in enamel production are more

213 pronounced and visible in the intermediate and occlusal thirds of the tooth (Blakey et al., 1994;

214 Newell et al., 2006).

Of the limited samples of comparable antiquity (minimally over 3000 years old on average) in the Global History of Human Health Database (Steckel and Rose, 2002; Steckel et

217 al., 2002), most populations demonstrated lower incidence of LEH compared to Buckeye Knoll

218 (59\% with at least one defect). The comparative sample with the closest frequency of Buckeye

219 Knoll LEH was Tlatilco. Tlatilco was a sedentary population with evidence of domesticated

220 plants and animals. Sedentary populations and those using domesticated plants were found to

221 have higher incidence of various stress indicators, and agriculturalists are documented as having

222 higher LEH incidence than foragers (Larsen, 1995; Starling and Stock, 2007). 

to parasite load (Bathurst, 2005). One example of this is found in Japan; prehistoric hunter-

225 gatherer-fishers have surprisingly high rates of LEH but these are sedentary complex stratified populations (Hoover and Matsumura, 2008; Temple, 2010). And, the higher incidence of defects is widely documented across the island and throughout time; given the abundance of resources and consistently high rates of LEH, a likelier explanation might be a genetic etiology (Hoover and Hudson, 2016; Hoover and Matsumura, 2008; Hoover and Williams, 2016). Coastal populations share a host of traits that may contribute to LEH defects, such as sedentism and reliance on domesticates. Although the Buckeye Knoll population likely relied at least partially on coastal resources, there is no evidence of domesticated plants or animals or sedentism at Buckeye Knoll.

The population most comparable to Buckeye Knoll is Windover. Windover has been assessed for LEH defects using the same methods used in the GHHD as well as the photogrammatic methods. Even when examining data on LEH defects using the unaided eye, Windover had a very high number of individuals affected by LEH defects. In the GHHD, 100\% represents a population completely unaffected by LEH, and the GHHD score for LEH in Windover was $=39.5 \%$ (Wentz et al., 2006). It is not clear why these two Early Archaic populations both appear to have a surprisingly high incidence of LEH, but a possible ecological explanation for the high overall incidence of LEH defects in this population is the climate shift during this time that may have caused physiological stress during periods of diminished resources.

\section{Conclusions}


247 History of Health Database of comparable age. However, these data are taken by unaided visual

248

249

250

251

252

253

254

255

256

257

258

259

260

261

262

263

264

265

266

267

268

269

270

271

272

273 assessment only, and photogrammetric methods have been shown to result in identification of greater numbers of LEH defects. However, Buckeye Knoll had fewer LEH defects compared with data collected using the same photogrammetric methods from Windover, a population of comparable antiquity. It is not clear whether the higher incidence of defects seen in these populations are entirely due to methodological differences in data collection, or whether an environmental factor such as the climate change documented during the Early Archaic period affected the health of coastal/riverine foragers such as the Windover and Buckeye Knoll populations.

\section{Acknowledgements}

We thank Glen Doran for access to the Buckeye Knoll population.

\section{References}

AlQahtani SJ, Hector MP, and Liversidge HM. 2014. Accuracy of dental age estimation charts: Schour and Massler, Ubelaker and the London Atlas. American Journal of Physical Anthropology 154(1):70-78.

Armelagos GJ, Goodman AH, Harper KN, and Blakey ML. 2009. Enamel hypoplasia and early mortality: Bioarcheological support for the Barker hypothesis. Evolutionary Anthropology: Issues, News, and Reviews 18(6):261-271.

Bathurst, R. R. 2005. Archaeological evidence of intestinal parasites from coastal shell middens. Journal of Archaeological Science, 32(1), 115-123.

Berbesque JC, and Doran GH. 2008. Brief communication: physiological stress in the Florida Archaic-enamel hypoplasia and patterns of developmental insult in early North American hunter-gatherers. American Journal of Physical Anthropology 136(3):351-356.

Blakey M, Leslie T, and Reidy J. 1994. Frequency and chronological distribution of dental enamel hypoplasia. American Journal of Physical Anthropology 95:371-383. 
Brook AH. 2009. Multilevel complex interactions between genetic, epigenetic and environmental factors in the aetiology of anomalies of dental development. Archives of Oral Biology 54(Supplement 1):S3-S17.

DeWitte SN, and Stojanowski CM. 2015. The Osteological Paradox 20 Years Later: Past Perspectives, Future Directions. Journal of Archaeological Research 23(4):397-450.

Golkari A, Sabokseir A, Pakshir HR, Dean MC, Sheiham A, and Watt RG. 2011. A comparison of photographic, replication and direct clinical examination methods for detecting developmental defects of enamel. BMC Oral Health 11(1):16.

Goodman AH. 1988. The chronology of enamel hypoplasias in an industrial population: A reappraisal of Sarnat and Shour (1941, 1942). Human Biology 60(5):781-791.

Goodman AH, and Armelagos GJ. 1989. Infant and childhood morbidity and mortality risks in archaeological populations. World Archaeology 21:225-243.

Guatelli-Steinberg D, Larsen CS, and Hutchinson DL. 2004. Prevalence and the duration of linear enamel hypoplasia: a comparative study of Neandertals and Inuit foragers. Journal of Human Evolution 47(1-2):65-84.

Hart PS, Aldred MJ, Crawford PJM, Wright NJ, Hart TC, and Wright JT. 2002. Amelogenesis imperfecta phenotype-genotype correlations with two amelogenin gene mutations. Archives of Oral Biology 47(4):261-265.

Herring DA, Saunders SR, and Katzenberg MA. 1998. Investigating the weaning process in past popuulations. American Journal of Physical Anthropology 105(4):425-440.

Hillson S, and Bond S. 1997. Relationship of enamel hypoplasia to the pattern of tooth crown growth: A discussion. American Journal of Physical Anthropology 104(1):89-103.

Hoover KC, and Hudson MJ. 2016. Resilience in prehistoric persistent hunter-gatherers in northwest Kyushu, Japan as assessed by population health and archaeological evidence. Quaternary International 405, Part B:22-33.

Hoover KC, and Matsumura H. 2008. Temporal variation and interaction between nutritional and developmental instability in prehistoric Japanese populations. American Journal of Physical Anthropology 137:469-478.

Hoover KC, and Williams FLE. 2016. Variation in regional diet and mandibular morphology in prehistoric Japanese hunter-gatherer-fishers. Quaternary International 405, Part B:101-109.

Katzenberg M, Herring D, and Saunders S. 1996. Weaning and infant mortality: evaluating the skeletal evidence. Yearbook of Physical Anthropology 39(S23):177-199.

Larsen CS. 1995. Biological Changes in Human Populations with Agriculture. Annual Review of Anthropology 24:185-213.

Lieverse AR, Link DW, Bazaliiskiy VI, Goriunova OI, and Weber AW. 2007. Dental health indicators of hunter-gatherer adaptation and cultural change in Siberia's Cis-Baikal. American Journal of Physical Anthropology 134(3):323-339.

Marlowe FW. 2005. Hunter-gatherers and human evolution. Evolutionary anthropology 14:5467.

Moggi-Cecchi J, Pacciani E, and Pinto-Cisternas J. 1994. Enamel hypoplasia and age at weaning in 19th-century Florence, Italy. American Journal of Physical Anthropology 93:299-306.

Newell, E. A., Guatelli-Steinberg, D., Field, M., Cooke, C., \& Feeney, R. N. 2006. Life history, enamel formation, and linear enamel hypoplasia in the Ceboidea. American journal of physical anthropology, 131(2), 252-260.

Reid DJ, and Dean MC. 2000. Brief Communication: The timing of linear hypoplasias on human anterior teeth. American Journal of Physical Anthropology 113:135-139. 
320

321

322

323

324

325

326

327

328

329

330

331

332

333

334

335

336

337

338

339

340

341

342

343

344

345

346

347

348

349

350

351

352

353

354

355

356

357

358

359

Ricklis RA, Weinstein RA, and Wells DC. 2012a. Archaeology and Bioarchaeology of the Buckeye Knoll Site (41VT98), Victoria County, Texas. Corpus Christi, Texas: Coastal Environments, Inc.

Ricklis RA, Weinstein RA, and Wells DC. 2012b. Archaeology and Bioarchaeology of the Buckeye Knoll Site (41VT98), Victoria County, Texas. Corpus Christi, Texas: Coastal Environments, Inc.

Ricklis RA, Weinstein RA, and Wells DC. 2012c. Archaeology and Bioarchaeology of the Buckeye Knoll Site (41VT98), Victoria County, Texas. Corpus Christi, Texas: Coastal Environments, Inc.

Sandberg PA, Sponheimer M, Lee-Thorp J, and Van Gerven D. 2014. Intra-tooth stable isotope analysis of dentine: A step toward addressing selective mortality in the reconstruction of life history in the archaeological record. American Journal of Physical Anthropology 155(2):281293.

Sarnat B, and Schour I. 1942. Enamel hypoplasia (chronologic enamel aplasia) in relation to systemic disease: A chronologic, morphologic, and etiologic classification. J Am Dent 29:397-418.

Sarnat BG, and Schour I. 1941. Enamel hypoplasia (chronologic enamel aplasia) in relation to systemic disease: A chronologic, morphologic, and etiologic classification. J Am Dent 28:1989-2000.

Scion. 2000-2001. Scion Image for Windows version Alpha 4.0.3.2. Maryland: Scion Corporation.

Starling AP, and Stock JT. 2007. Dental Indicators of Health and Stress in Early Egyptian and Nubian Agriculturalists. Am J Phys Anthropol 134:520-528.

Steckel RH, and Rose JC, editors. 2002. The Backbone of History : Health and Nutrition in the Western Hemisphere. Cambridge: Cambridge University Press.

Steckel RH, Sciulli PW, and Rose JC. 2002. A health index from skeletal remains. In: Steckel RH, and Rose JC, editors. The Backbone of History: Health and Nutrition in the Western Hemisphere. New York: Cambridge University Press. p 61-93.

Temple DH. 2010. Patterns of systemic stress during the agricultural transition in prehistoric Japan. American Journal of Physical Anthropology 142:112-124.

Walter BS, and DeWitte SN. 2017. Urban and rural mortality and survival in Medieval England. Annals of Human Biology 44(4):338-348.

Wentz, R. K., Tucker, B., Krigbaum, J., \& Doran, G. H. 2006. Gauging differential health among the sexes at Windover (8Br246) using the Western Hemisphere Health Index. Memórias do Instituto Oswaldo Cruz, 101, 77-83.

Yaussy SL, DeWitte SN, and Redfern RC. 2016. Frailty and famine: Patterns of mortality and physiological stress among victims of famine in medieval London. American Journal of Physical Anthropology 160(2):272-283.

Zilberman U, Smith P, Piperno M, and Condemi S. 2004. Evidence of amelogenesis imperfecta in an early African Homo erectus. Journal of Human Evolution 46(6):647-653. 


\section{Table $\mathbf{1}$ (on next page)}

Descriptive Information for Comparative Sites, including Domesticated Plants/Animals 
1 Table 1. Descriptive Information for Comparative Sites, including Domesticated Plants/Animals

\begin{tabular}{llllllc}
\hline Site & $\mathbf{n}$ & Animals & Plants & Climate & Settlement & Site Date \\
Preceramico & 60 & None & None & Subtropical & Mobile & $2000-4000$ \\
Tlatilco & 80 & Some & Maize, beans, & Temperate & Small / Medium & $2930-3250$ \\
Realto & 34 & Some & None & Tropical & Settled Dispersed & $3450-5876$ \\
Sta. Elena & 39 & None & None & Tropical & Mobile & $6600-8250$ \\
$\begin{array}{l}\text { Buckeye } \\
\text { Knoll }\end{array}$ & 92 & None & None & Subtropical & Mobile & $3500-8500$ \\
\hline
\end{tabular}

2

3

4 
Table 2 (on next page)

LEH Count and Frequency by Demographic Category, Buckeye Knoll

${ }^{1}$ No sex identification ${ }^{2}$ Loose, not affiliate with any burial 
1 Table 2. LEH Count and Frequency by Demographic Category, Buckeye Knoll

\begin{tabular}{|l|c|c|c|c|c|c|c|c|c|c|c|}
\hline & $\begin{array}{c}\text { Total } \\
\text { n }\end{array}$ & \multicolumn{2}{|c|}{ 0 LEH } & \multicolumn{2}{|c|}{$\mathbf{1}$ LEH } & \multicolumn{2}{|c|}{ 2 LEH } & \multicolumn{2}{|c|}{3 LEH } & \multicolumn{2}{|c|}{ 4 LEH } \\
\hline & & n & Freq & n & Freq & n & Freq & n & Freq & n & Freq \\
\hline Males & 5 & 1 & 0.20 & 2 & 0.40 & 1 & 0.20 & 1 & 0.20 & 0 & 0.00 \\
\hline Females & 13 & 5 & 0.38 & 5 & 0.38 & 2 & 0.15 & 1 & 0.08 & 0 & 0.00 \\
\hline Juveniles & 6 & 0 & 0.00 & 1 & 0.17 & 0 & 0.00 & 3 & 0.50 & 2 & 0.33 \\
\hline Adult $^{1}$ & 9 & 7 & 0.78 & 1 & 0.11 & 1 & 0.11 & 0 & 0.00 & 0 & 0.00 \\
\hline Canines $^{2}$ & 59 & 25 & 0.42 & 23 & 0.39 & 8 & 0.14 & 2 & 0.03 & 1 & 0.02 \\
\hline
\end{tabular}

$2{ }^{1}$ No sex identification

$3 \quad{ }^{2}$ Loose, not affiliate with any burial

4

5 
Table 3 (on next page)

LEH Count and Frequency, Comparative populations. 
1 Table 3. LEH Count and Frequency, Comparative Populations

\begin{tabular}{|l|c|c|c|c|c|c|c|}
\hline \multirow{2}{*}{ Site } & $\begin{array}{c}\text { Total } \\
\text { n }\end{array}$ & \multicolumn{2}{|c|}{ 0 LEH } & \multicolumn{2}{c|}{ 1 LEH } & \multicolumn{2}{|c|}{ 2+LEH } \\
\hline & & Count & Freq & Count & Freq & Count & Freq \\
\hline Preceramico & 60 & 41 & 0.68 & 16 & 0.27 & 3 & 0.05 \\
\hline Tlatilco & 80 & 41 & 0.51 & 32 & 0.40 & 7 & 0.09 \\
\hline Realto & 34 & 31 & 0.91 & 3 & 0.09 & 0 & 0.00 \\
\hline Sta. Elena & 39 & 38 & 0.97 & 1 & 0.03 & 0 & 0.00 \\
\hline Buckeye Knoll & 92 & 38 & 0.41 & 32 & 0.35 & 22 & 0.24 \\
\hline
\end{tabular}

2

3

4 
Table 4 (on next page)

LEH Descriptive Statistics, Buckeye Knoll and Windover 
1 Table 4. LEH Descriptive Statistics, Buckeye Knoll and Windover

\begin{tabular}{lcc|cc} 
& \multicolumn{2}{c|}{ Mandibular Canine } & \multicolumn{2}{c}{ Maxillary Canine } \\
$\mathrm{N}$ & Windover & Buckeye Knoll & Windover & Buckeye Knoll \\
& 59 & 43 & 48 & 2 \\
\hline Mean LEH & 2.78 & 1.07 & 2 & 0.7 \\
\hline Median LEH & 3 & 1 & 2 & 1 \\
\hline Mode LEH & 3 & 0 & $1-4$ & 0 \\
\hline Range & $1-6$ & $1-4$ & 0.99 & 0.85 \\
\hline SD & 1.34 & 1.06 & & \\
\hline
\end{tabular}

2

3

4 